\title{
Czy preparaty propionianu flutykazonu z salmeterolem z pMDI są takie same? Doniesienie wstępne
}

\section{Are all pMDI fluticasone propionate + salmeterol products the same? Preliminary report}

\author{
Tomasz R. Sosnowski ${ }^{1}$, Andrzej Emeryk ${ }^{2}$, Kamil Janeczek ${ }^{2}$, Justyna Emeryk-Maksymiuk ${ }^{3}$ \\ ${ }^{1}$ Katedra Inżynierii Procesów Zintegrowanych, Wydział Inżynierii Chemicznej i Procesowej, \\ Politechnika Warszawska \\ Kierownik: prof. dr hab. inż. Tomasz R. Sosnowski \\ ${ }^{2}$ Klinika Chorób Płuc i Reumatologii Dziecięcej, Uniwersytet Medyczny w Lublinie \\ Kierownik: prof. dr hab. n. med. Andrzej Emeryk \\ ${ }^{3}$ Katedra i Zakład Pielęgniarstwa Internistycznego, Uniwersytet Medyczny w Lublinie \\ Kierownik: dr hab. n. med. Agnieszka Zwolak
}

\begin{abstract}
Streszczenie:
W pracy przedstawiono wyniki badania oceniającego podstawowe parametry charakteryzujące chmurę aerozolową (wartość średnicy aerodynamicznej odpowiadająca medianie rozkładu masowego wielkości cząstek, frakcja cząstek drobnych, geometryczne odchylenie standardowe) generowaną przez inhalatory ciśnieniowe dozujące zawierające kombinację glikokortykosteroidu z $\beta_{2}$-mimetykiem długo działającym. Porównano trzy dostępne na polskim rynku produkty propionianu flutykazonu z salmeterolem (jeden referencyjny oraz dwa generyczne). Na podstawie wyznaczonych parametrów określono depozycję wdychanego aerozolu na poszczególnych piętrach układu oddechowego. Stwierdzono niewielkie różnice między badanymi produktami.
\end{abstract}

\begin{abstract}
:
The paper presents the results of a study evaluating the basic parameters characterizing the aerosol cloud (aerodynamic diameter value which corresponding to the median of the mass particle size distribution, fine particle fraction, geometric standard deviation) generated by pressurized metered dose inhaler containing a combination of a glucocorticosteroid with a long-acting $\beta_{2}$-mimetic. Three fluticasone propionate products available on the Polish market were compared with salmeterol (one reference and two generic). Based on the determined parameters, the inhaled aerosol deposition on particular levels of the respiratory system was determined. There were slight differences between the tested products.
\end{abstract}

Słowa kluczowe: inhalator ciśnieniowy dozujący, propionian flutykazonu, salmeterol, chmura aerozolowa, depozycja w drogach oddechowych, astma, dorośli

Key words: pressurized metered dose inhaler, fluticasone propionate, salmeterol, aerosol cloud, lung deposition, asthma, adults

Wstęp

Połączenie propionianu flutykazonu (PF) z salmeretolem (SALM) w jednym inhalatorze jest kombi- nacją wziewnego glikokortykosteroidu (wGKS) z długo działającym $\beta_{2}$-mimetykiem (LABA, long-acting 
$\beta$-agonist) bardzo często stosowaną w terapii chorób obturacyjnych dróg oddechowych, głównie w astmie $[1,2]$. Zgodnie z najnowszymi rekomendacjami Global Initiative for Asthma (GINA) połączenie wGKS + LABA jest postępowaniem preferowanym u chorych $\geq 12$. r.ż. na wszystkich stopniach terapii, a u dzieci w wieku 6-11 lat od trzeciego do piątego stopnia [1].

Kombinacje PF i SALM występują w inhalatorze ciśnieniowym dozującym (pMDI, pressurized metered dose inhaler) oraz kilku typach inhalatorów suchego proszku (DPI, dry powder inhaler). Połącznie PF + SALM z pMDI i DPI jest znane na rynku od ok. 30 lat i oprócz kombinacji budezonidu i formoterolu z DPI jest to najlepiej przebadane połączenie wGKS + LABA pod względem efektywności i bezpieczeństwa u chorych na astmę, w tym także u dzieci. Liczba publikacji w bazie PubMed dotycząca kombinacji PF + SALM dostępnych $\mathrm{w}$ pMDI lub DPI na 1.08.2021 r. wynosiła 813 , w tym 45 przeglądów systematycznych z metaanalizą [3]. Ze względu na wysoką skuteczność i bezpieczeństwo oraz stosunkowo niską cenę połączenia $\mathrm{PF}+\mathrm{SALM}$ w ostatnich 10 latach pojawiło się wiele produktów generycznych zawierających tę kombinację względem produktu referencyjnego, zarówno w pMDI, jak i w DPI [4-8]. Obecnie w Polsce jest dostępnych kilka połączeń PF + SALM w pMDI i w DPI [9].

\section{Cel}

Celem pracy była ocena chmury aerozolowej (rozkładu wielkości cząstek) dostępnych na polskim rynku kombinacji PF + SALM z pMDI wraz z próbą oceny depozycji płucnej badanych preparatów.

\section{Materiał i metody}

W ramach badania dokonano oceny następujących produktów inhalacyjnych, które zakupiono w losowo wybranej aptece w Warszawie:

1. Comboterol $125 \mu \mathrm{g} / 25 \mu \mathrm{g}$ (propionian flutykazonu + salmeterol - Lekam) (LOT no. GB91760, data ważności: październik 2021 r.)

2. Comboterol $250 \mu \mathrm{g} / 25 \mu \mathrm{g}$ (propionian flutykazonu + salmeterol - Lekam) (LOT no. GB00606, data ważności: marzec 2022 r.)

3. Duexon $125 \mu \mathrm{g} / 25 \mu \mathrm{g}$ (propionian flutykazonu + salmeterol - Adamed Pharma) (LOT no. 1071720, data ważności: listopad 2022 r.)

4. Duexon $250 \mu \mathrm{g} / 25 \mu \mathrm{g}$ (propionian flutykazonu + salmeterol - Adamed Pharma) (LOT no. 1063120, data ważności: listopad 2022 r.)
5. Seretide $125 \mu \mathrm{g} / 25 \mu \mathrm{g}$ (propionian flutykazonu + salmeterol - GSK Ireland) (LOT no. 733M, data ważności: styczeń 2023 r.)

6. Seretide $250 \mu \mathrm{g} / 25 \mu \mathrm{g}$ (propionian flutykazonu + salmeterol - GSK Ireland) (LOT no. 8L8X, data ważności: sierpień 2022 r.).

Pomiary rozkładu wielkości cząstek wykonano metodą dyfrakcji laserowej (spektrometr aerozolowy Spraytec - Malvern Scientific, Wielka Brytania). Jest ona dobrze zweryfikowana $\mathrm{w}$ literaturze jako równoważna metodzie impaktorowej w badaniu nebulizatorów i pMDI $[10,11]$. Wyniki próbkowane $\mathrm{z}$ częstotliwością $1 \mathrm{kHz}$ uzyskane w tzw. stabilnej fazie emisji aerozolu (tj. przy względnej stałości sygnału transmisji i wartości Dv50) uśredniono w czasie. Na podstawie uzyskanych rozkładów wielkości cząstek wyznaczono średnice centylowe rozkładu objętościowego/wagowego: Dv10, Dv50 (mediana rozkładu), Dv90, geometryczne odchylenie standardowe (GSD, geometric standard deviation) oraz zawartość (w \% wag.) frakcji cząstek drobnych $(<5 \mu \mathrm{m}$, czyli FPF [fine particle fraction]). W analizowanym przypadku wartość Dv50 oznacza także wartość średnicy aerodynamicznej odpowiadającą medianie rozkładu masowego wielkości cząstek (MMAD, mass median aerodynamic diameter), ponieważ zasadnicza masa cząstek aerozolowych uzyskiwanych z badanych inhalatorów pMDI jest mniejsza od tzw. frakcji balistycznej (tj. od ok. 10-12 $\mu \mathrm{m}$ ). Każdy inhalator badano dwukrotnie. Na podstawie uzyskanych wyników średnich MMAD i GSD obliczono depozycję regionalną wdychanego aerozolu, korzystając z kalkulatora depozycji (MPPD, multiple-path particle dosimetry model) wersja 2.1 [12, 13]. Obliczenia wykonano dla symetrycznego modelu płuca [14] przy następujących parametrach charakteryzujących przeciętnego zdrowego dorosłego:

- FRC (czynnościowa pojemność zalegająca) $=3300 \mathrm{ml}$

- objętość górnych dróg oddechowych (jama ustna $\mathrm{i}$ gardło) $=50 \mathrm{ml}$

- objętość aerozolu pobierana przy wdechu (podczas użycia pMDI) $=1200 \mathrm{ml}$

- $\quad$ czas $w d e c h u=4 \mathrm{~s}$

- $\quad$ czas wstrzymania oddechu po inhalacji $=8 \mathrm{~s}$.

Badania i obliczenia przeprowadzono w laboratorium Katedry Inżynierii Procesów Zintegrowanych Wydziału Inżynierii Chemicznej i Procesowej Politechniki Warszawskiej od czerwca do lipca 2021 r. Badania wykonano dla trzech prób dla każdego z produktów wyszczególnionych powyżej. Dla wyników uzyska- 
nych w kolejnych próbach (tj. wartości centylowych, GSD, MMAD i FPF) wyznaczono wartości średnie (X) i odchylenia standardowe (SD, standard deviation). Obliczenia przewidywanej depozycji regionalnej inhalowanego aerozolu w układzie oddechowym wykonano dla średnich wartości MMAD i GSD.

\section{Wyniki}

$\mathrm{Na}$ rycinie 1 przedstawiono przykładowy wykres rozkładu wielkości cząstek uzyskanego w poje- dynczym pomiarze. Rozkład ten ma charakter logarytmiczno-normalny, co umożliwia poprawne określenie polidyspersyjności aerozolu za pomocą wartości GSD.

W tabelach 1 i 2 zestawiono dane rozkładów wielkości cząstek wyznaczone na podstawie pomiarów z użyciem dyfrakcyjnego spektrometru aerozolowego.

Porównanie danych zamieszczonych w tabelach 1 i 2 pozwala potwierdzić, że analogiczne produkty (pod względem nominalnej dawki molekuł leków) wykazują nieznaczne, jednakże zauważalne różnice w jakości aerozolu uzyskiwanego z pMDI. Przejawia

Rycina 1. Przykładowy rozkład wielkości czastek aerozolowych (linia czarna) wraz z dopasowaniem krzywej rozkładu logarytmiczno-normalnego (linia zielona).

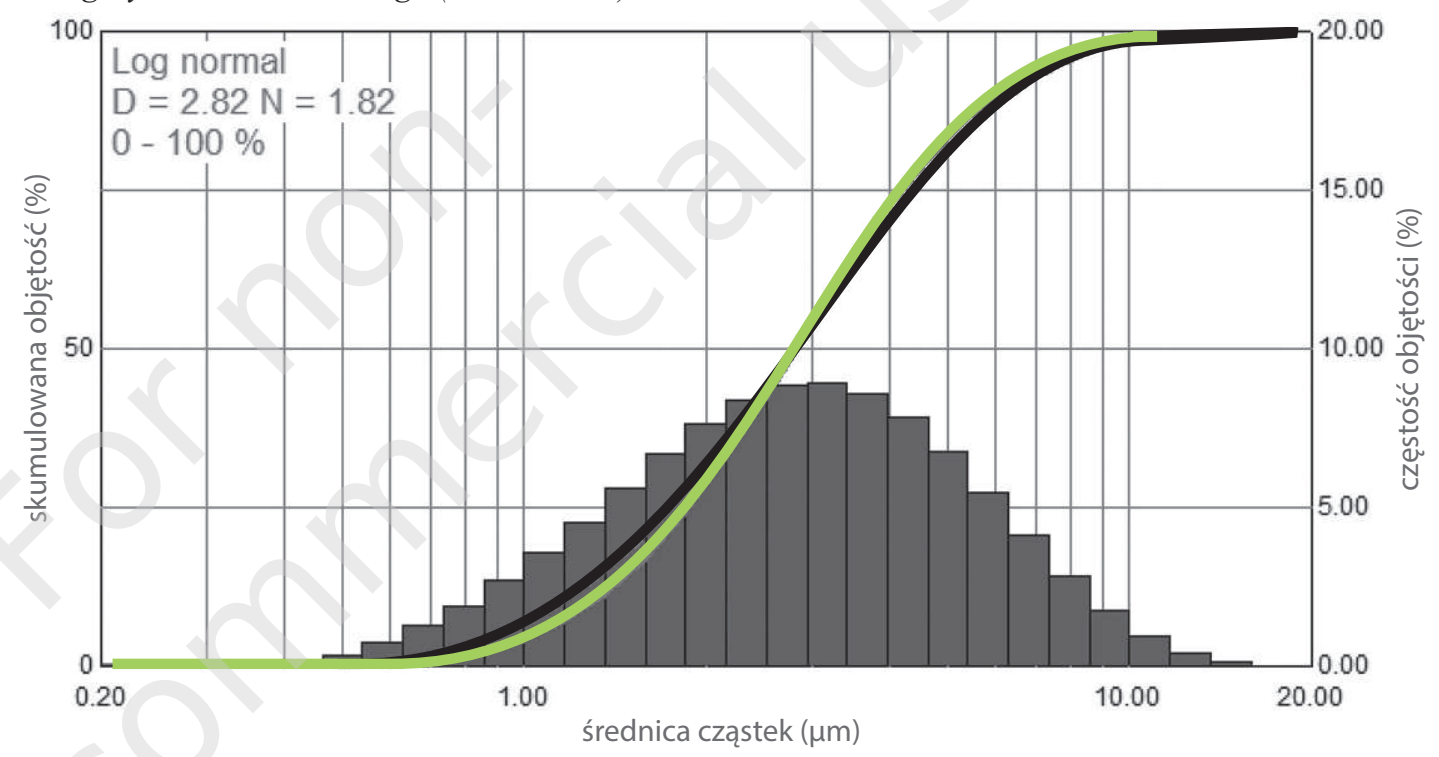

Tabela 1. Dane rozkładu wielkości cząstek dla trzech produktów propionianu flutykazonu z salmeterolem 125/25 $\mu \mathrm{g}$.

\begin{tabular}{|c|c|c|c|c|c|c|}
\hline \multirow{2}{*}{ Badane parametry } & \multicolumn{2}{|c|}{ Seretide 125/25 $\mu g$} & \multicolumn{2}{|c|}{ Comboterol 125/25 ㅁg } & \multicolumn{2}{|c|}{ Duexon 125/25 pg } \\
\hline & $x$ & SD & $x$ & SD & $x$ & SD \\
\hline Dv10 & 1,16 & 0,07 & 1,37 & 0,30 & 1,16 & 0,15 \\
\hline Dv50 (MMAD) & 2,61 & 0,07 & 3,27 & 0,44 & 2,71 & 0,10 \\
\hline Dv90 & 5,59 & 0,14 & 7,63 & 1,58 & 6,06 & 0,55 \\
\hline FPF [\%] & 85,81 & 0,96 & 73,84 & 8,86 & 83,28 & 3,19 \\
\hline GSD & 1,77 & 0,05 & 1,86 & 0,21 & 1,84 & 0,15 \\
\hline
\end{tabular}

X - średnia arytmetyczna; SD (standard deviation) - odchylenie standardowe.

Tabela 2. Dane rozkładu wielkości cząstek dla trzech produktów propionianu flutykazonu z salmeterolem 250/25 $\mu g$.

\begin{tabular}{|c|c|c|c|c|c|c|}
\hline \multirow{2}{*}{ Badane parametry } & \multicolumn{2}{|c|}{ Seretide 250/25 मg } & \multicolumn{2}{|c|}{ Comboterol 250/25 g } & \multicolumn{2}{|c|}{ Duexon 250/25 pg } \\
\hline & $x$ & SD & $x$ & SD & $x$ & SD \\
\hline Dv10 & 1,22 & 0,06 & 1,47 & 0,14 & 1,43 & 0,16 \\
\hline Dv50 (MMAD) & 3,07 & 0,04 & 3,64 & 0,60 & 3,05 & 0,28 \\
\hline Dv90 & 6,62 & 0,25 & 8,24 & 1,56 & 6,38 & 0,51 \\
\hline FPF [\%] & 77,92 & 1,48 & 68,55 & 9,85 & 79,82 & 4,13 \\
\hline GSD & 1,84 & 0,07 & 1,86 & 0,08 & 1,71 & 0,05 \\
\hline
\end{tabular}

X - średnia arytmetyczna; SD (standard deviation) - odchylenie standardowe. 
się to rozrzutem zarówno wartości MMAD (od ok. $2,6 \pm 0,1 \mu \mathrm{m}$ do ok. 3,3 $\pm 0,4 \mu \mathrm{m}$ w przypadku produktów $125 / 25 \mu \mathrm{g}$ oraz od ok. $3,1 \pm 0,3 \mu \mathrm{m}$ do ok. 3,6 $\pm 0,6$ $\mu \mathrm{m} w$ przypadku produktów $250 / 25 \mu \mathrm{g}$ ), jak i wartości FPF (od ok. $74 \pm 9 \%$ do ok. $86 \pm 1 \% \mathrm{w}$ przypadku produktów 125/25 $\mu$ g oraz od ok. $69 \pm 10 \%$ do ok. $80 \pm 4 \%$ w przypadku produktów 250/25 $\mu \mathrm{g}$ ). Różna jest także polidyspersyjność aerozolu (charakteryzowana wartością GSD), która zmienia się w zakresie od 1,77 $\pm 0,05$ do $1,86 \pm 0,21 \mathrm{w}$ przypadku produktów $125 / 25 \mu \mathrm{g}$ oraz od $1,71 \pm 0,05$ do $1,86 \pm 0,08 \mathrm{w}$ przypadku produktów $250 / 25 \mu$ g. Produkt referencyjny (Seretide) oraz jeden z generyków (Duexon) charakteryzują się większą powtarzalnością wytwarzania chmury aerozolowej, co potwierdzają niskie wartości SD parametrów wyznaczonych z kolejnych prób pomiarowych.

$\mathrm{Na}$ rycinie 2 przedstawiono porównanie wyników obliczeń regionalnej depozycji cząstek aerozolowych w układzie oddechowym wykonane dla średnich wartości MMAD i GSD (tab. 1). ustnej i gardle (region $\mathrm{H}$ ) - na poziomie 7-8\%, co jest korzystne z punktu widzenia bezpieczeństwa terapii wGKS. Dla Comboterolu depozycja w tym obszarze wynosi 10-13\%, zaś dla leku referencyjnego (Seretide) od $7 \%(125 / 25 \mu \mathrm{g})$ do $9 \%(250 / 25 \mu \mathrm{g})$.

\section{Dyskusja}

Inhalatory ciśnieniowe dozujące należą do urządzeń inhalacyjnych najczęściej stosowanych w codziennej praktyce lekarskiej. W pMDI jest bowiem dostępna większość klas leków przyjmowanych w terapii astmy lub przewlekłej obturacyjnej chorobie płuc (POChP) - brak jedynie długo działających leków przeciwcholinolitycznych (LAMA, long-acting muscarinic antagonists) oraz kombinacji LABA + LAMA [9].

Rejestracja nowego leku generycznego wGKS + LABA wymaga spełnienia wielu wymogów [15], szczególnie rygorystycznych w USA [16], mających wykazać analogiczny profil skuteczności terapeutycz-

Rycina 2. Porównanie przewidywanej depozycji regionalnej cząstek aerozolowych dostarczanych przez badane produkty.

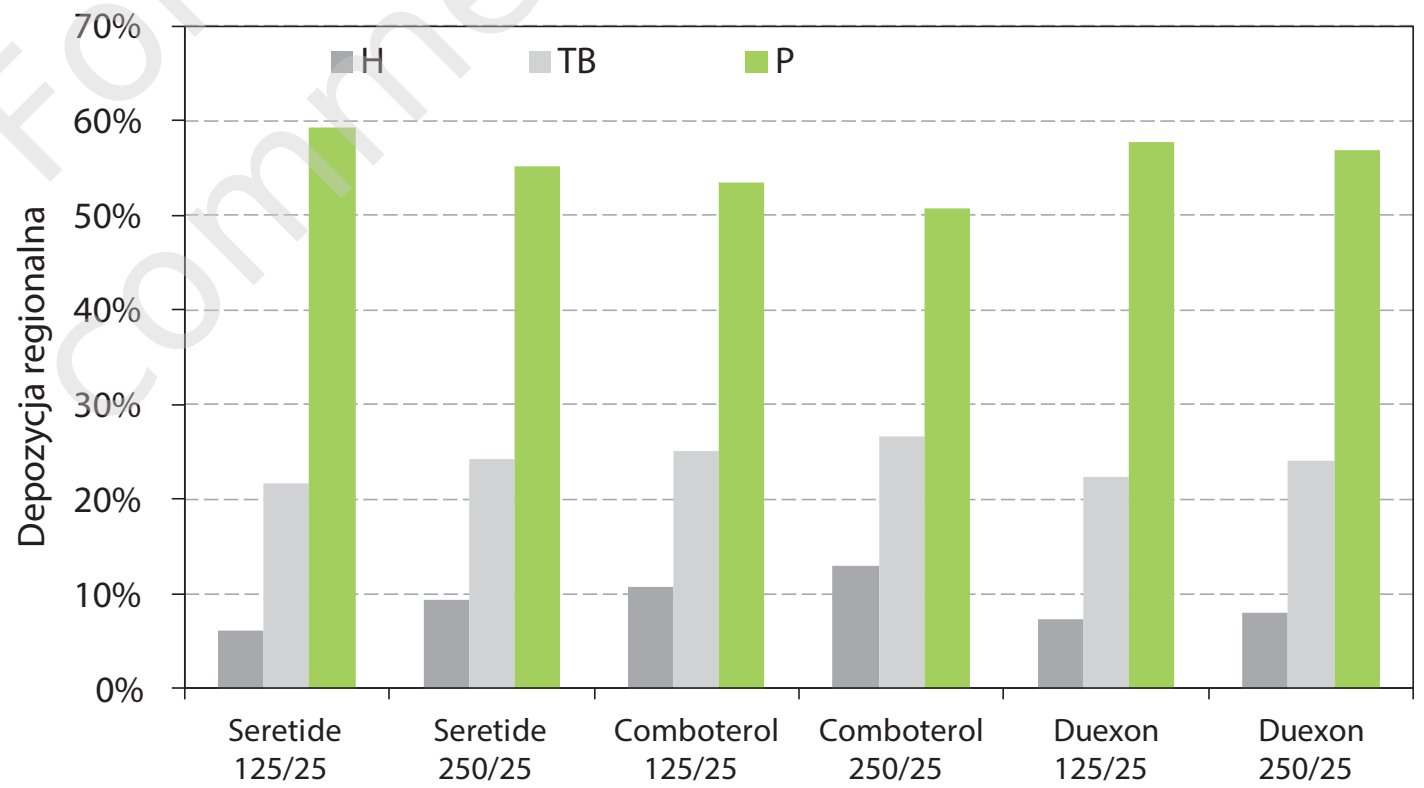

H - depozycja w jamie ustnej i gardle; TB - depozycja w centralnych drogach oddechowych (duże oskrzela); P - depozycja obwodowa.

Depozycja obwodowa (region $\mathrm{P}$ na rycinie 2) cząstek leku w przypadku produktu referencyjnego jest na poziomie 55-60\%. Podobną wartość osiąga w obu dawkach produkt Duexon. Nieco niższy poziom depozycji zaobserwowano dla Comboterolu (50-55\%), dla którego wyższa jest z kolei depozycja w większych oskrzelach (region TB) - nieco powyżej 25\%, w porównaniu z ok. 20-25\% dla Seretide i Duexonu. Duexon charakteryzuje się niską depozycją w jamie nej i bezpieczeństwa względem leku referencyjnego. Podobieństwo produktu generycznego do oryginalnego wymagane przez Agencję ds. Żywności i Leków (FDA, Food and Drug Administration) lub Europejską Agencję Leków (EMA, European Medicines Agency) pozostawia pewien margines - trzeba bowiem udowodnić zbliżoną, ale nie identyczną jakość aerozolu [17]. Taki był też cel naszego badania. Jednakże opisane we wstępie zalety kombinacji PF + SALM skłaniają kolejne firmy 
farmaceutyczne do wprowadzania na rynek kolejnych leków generycznych, w tym także w kraju.

Badane w pracy produkty pMDI cechują się zbliżonymi właściwościami wytwarzanych aerozoli, co wykazano, używając wystandaryzowanej, nowoczesnej metody analizy chmury aerozolowej. Jednakże dla produktów Seretide i Duexon zaobserwowano mniejszy rozrzut wartości MMAD i FPF. Oznacza to większą powtarzalność wielkości cząstek aerozolowych inhalowanych leków niż w przypadku badanych produktów Comboterol. Ponadto wykonano symulację depozycji płucnej badanych leków w trzech obszarach: w jamie ustnej i gardle (górne drogi oddechowe), w centralnych drogach oddechowych oraz oskrzelach obwodowych. Dla aerozolu emitowanego z produktów Duexon, podobnie jak z produktów Seretide, jest przewidywana mniejsza depozycja w górnych drogach oddechowych vs preparat Comboterol. To może przekładać się na mniejsze miejscowe skutki uboczne tych preparatów (dotyczy to bezpieczeństwa stosowania wGKS). Wyniki prezentowanego badania należy traktować jako doniesienie wstępne.

\section{Podsumowanie}

Badane preparaty $\mathrm{w}$ pMDI charakteryzują się zbliżonymi właściwościami produkowanych aerozoli opisywanymi przez wartości Dv10, Dv90, FPF i MMAD.

Produkty Seretide i Duexon cechuje mniejszy rozrzut wartości MMAD i FPF, co oznacza większą powtarzalność produkowanych dawek leków niż w przypadku badanych produktów Comboterol.

Aerozol emitowany $\mathrm{z}$ produktów Seretide i Duexon w mniejszym stopniu deponuje się w górnych drogach oddechowych niż preparat Comboterol.

\section{Piśmiennictwo}

1. Global Strategy for Asthma Management and Prevention, Global Initiative for Asthma (GINA). Update 2021.

2. Cloutier MM, Baptist AP, Blake KV et al; Expert Panel Working Group of the National Heart, Lung, and Blood Institute (NHLBI) administered and coordinated National Asthma Education and Prevention Program Coordinating Committee (NAEPPCC). 2020 Focused Updates to the Asthma Management Guidelines: A Report from the National Asthma Education and Prevention Program Coordinating Committee Expert Panel Working Group. J Allergy Clin Immunol. 2020; 146(6): 1217-70.
3. https://pubmed.ncbi.nlm.nih.gov/?term=fluticasone+ propionate + salmeterol + combination\&sort=date (access: 1.08.2021).

4. Mehta R, Daley-Yates PT, Jenkins K et al. Pharmacokinetics of fluticasone propionate and salmeterol delivered as a combination dry powder via a capsule-based inhaler and a multi-dose inhaler. Pulm Pharmacol Ther. 2014; 29(1): 66-73.

5. Paik J, Scott LJ, Pleasants RA. Fluticasone Propionate/

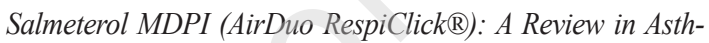
ma. Clin Drug Investig. 2018; 38(5): 463-73.

6. Kupczyk M, Majak P, Kuna $P$ et al. A new formulation of fluticasone propionate/ salmeterol in a metered-dose inhaler (MDI HFA) allows for the reduction of a daily dose of corticosteroid and provides optimal asthma control - A randomized, multi-center, non-inferiority, phase IV clinical study. Respir Med. 2021; 176: 106274.

7. https://www.mp.pl/pacjent/leki/lek/98834,Duexon-aerozolinhalacyjny.-zawiesina (access: 2.08.2021).

8. Tashkin DP, Koltun A, Wallace R. A generic fluticasone propionate and salmeterol dry powder inhaler: Evidence of usability, function, and robustness. Allergy Asthma Proc. 2021; 42(1): 30-5

9. Emeryk A, Janeczek K, Sosnowski TR et al. Połaczenia glikokortykosteroidu $z$ dlugo działajacym $\beta_{2}$-mimetykiem $w$ inhalatorze ciśnieniowy dozujacym - jakie, komu, kiedy? Alergoprofil. 2021; 3 (wdruku).

10. Mao L, Wilcox D, Kippax P. Laser diffraction particle size analysis: a powerful tool for rapidly screening nebulizer formulations. Drug Delivery Techn. 2010; 10: 64-7.

11. Haynes A, Shaik MS, Krarup $H$ et al. Evaluation of the Malvern Spraytec with inhalation cell for the measurement of particle size distribution from metered dose inhalers. J Pharm Sci. 2004; 93(2): 349-63.

12. Applied Research Associates, Inc. 2021. https://www.ara. com/mppd (access: 2.08.2021).

13. Miller FJ, Asgharian B, Schroeter JD et al. Improvements and additions to the Multiple Path Particle Dosimetry model. J Aerosol Sci. 2016; 99: 14-26.

14. Yeh HC, Schum GM. Models of human lung airways and their application to inhaled particle deposition. Bull Math Biol. 1980; 42(3): 461-80.

15. Guideline on the requirements for clinical documentation for orally inhaled products (OIP) including the requirements for demonstration of therapeutic equivalence between two inhaled products for use in the treatment of asthma and chronic obstructive pulmonary disease (COPD) in adults and for use in the treatment of asthma in children and adolescents. EMA, Doc. Ref. CPMP/EWP/4151/00 Rev. 1, London 2009. https://www.ema.europa.eu/en/documents/scientific-guideline/guideline-requirements-clinical-documentation-orally-inhaled-products-oip-including-requirements_en.pdf (access: 2.08.2021). 
16. Draft Guidance on Fluticasone Propionate; Salmeterol Xinafoate. Recommended May 2019. https://www.accessdata.fda. gov/drugsatfda_docs/psg/Fluticasone\%20Propionate;\%20 Salmeterol\%20Xinafoate\%20Inhalation\%20Aerosol\%20Metered $\% 20 N D A \% 20021254 \% 20 P S G \% 20$ Page $\% 20 R C \% 20$ May\%202019.pdf (access: 3.08.2021).

17. Pirożynski M, Sosnowski TR. Inhalation devices: from basic science to practical use, innovative vs generic products. Expert Opin Drug Deliv. 2016; 13(11): 1559-71.

ORCID:

T.R. Sosnowski - ID - http://orcid.org/0000-0002-6775-3766

A. Emeryk - ID - http://orcid.org/0000-0003-1853-8696

K. Janeczek - ID - http://orcid org/0000-0002-8163-873X

J. Emeryk-Maksymiuk - ID - http://orcid.org/0000-0003-2709-0424

Wkład autorów/Authors' contributions:

T.R. Sosnowski: metodologia, wykonanie i maszynopis; A. Emeryk: koncepcja i maszynopis; K. Janeczek: korekta maszynopisu; J. Emeryk-Maksymiuk: piśmiennictwo, korekta maszynopisu.

Konflikt interesów/Conflict of interests:

Nie występuje.
Finansowanie/Financial support:

Nie występuje.

Etyka/Ethics:

Treści przedstawione w artykule są zgodne z zasadami Deklaracji Helsińskiej, dyrektywami EU oraz ujednoliconymi wymaganiami dla czasopism biomedycznych. Copyright: (C) Medical Education sp. Z 0.0. This is an Open Access article distributed under the terms of the Attribution-NonCommercial 4.0 International (CC BY-NC 4.0). License (https://creativecommons.org/licenses/by-nc/4.0/), allowing third parties to copy and redistribute the material in any medium or format and to remix, transform, and build upon the material, provided the original work is properly cited and states its license.

Adres do korespondencji

prof. dr hab. n. med. Andrzej Emeryk

Klinika Chorób Płuc i Reumatologii Dziecięcej, Uniwersytet Medyczny w Lublinie, Uniwersytecki Szpital Dziecięcy w Lublinie 20-093 Lublin, ul. prof. Antoniego Gębali 6 tel.: (+48) 817185477 e-mail: emerykandrzej@gmail.com 